\title{
Behavioural Correlates of Neutering Male Dogs - a Question of Breed?
}

\author{
Keywords: Castration; Retriever; Shepherds; Hunting Dogs; Terrier: \\ Personality traits; Panic; Aggression
}

\begin{abstract}
Castration of dogs is often conducted as a preventive measure against diseases and undesirable behaviour. While female dogs are preferably neutered for medical reasons, owners of male dogs hope for an improvement in behavior. Although there is a lack of scientific knowledge on this subject, neutering is often conducted to get a more trainable and less aggressive dog.

The aim of this study is to examine castration from an ethological perspective and to reveal possible behavioural changes after castration related to breed.

An online study was conducted consisting of two different questionnaires about the dog's personality. A total of 242 dog owners participated in the study concerning specific behaviour problems ( $n$ $=130$ intact and 112 neutered males). Another 211 owners of males ( $n=115$ intact, 96 neutered) completed the questionnaire about personality traits (dog sociability, trainability, emotional stability and extraversion) based on Turcsán et al. 2011.

Four breed categories were formed following Parker et al. (2017): shepherds, retrievers, terriers, and hunting Dogs. Our study reveals that intact males are bolder than neutered males. Intact males have lower aggression scores than neutered ones. Castrated males show significantly more panic behavior (multinomial logistic Regression, $p=$ 0.04).

Intact shepherds are bolder than neutered ones (Mann-Whiney-U-Test: $p=0.03$ ) and intact terriers are bolder than neutered terriers (MannWhitney-U = Test: $p=0.04$ ). Intact terriers scored lower for aggression than neutered ones. With these results and the data of previous studies, we question castration to modify behavior, as a measure for reproductive control and as a preventive measure against diseases.
\end{abstract}

\section{Introduction}

At the beginning of industrialization, breeding goals changed from pure specialists, such as hunting and retrieving dogs, to companion dogs, which should rather take on the function of social partners [1]. Today, classic working dogs such as the Magyar Vizsla (hunting dog) or the Australian Shepherd (herding dog) are increasingly found in the home as family members. Today's requirements for breeders include that dogs can adjust to urban living conditions and that they meet the social needs of humans as family members [32,42].

Although the number of dog breeds has increased significantly over the past century and a half, relatively little empirical research has focused on the behavioral characteristics of breeds. However, it is generally accepted that different breeds exhibit different behavioral repertoires due to selective pressures exerted by humans $[5,18,41]$. Brewer et al. (2002) define a dog breed as a group of individuals within the C. lupus familiaris subspecies that are very similar on the basis of a number of characteristics that have been shown to differ from other groups [6].

The more traditional and widely used methods of categorizing breeds have been promoted by various national and international cynological associations, where dog breeds are divided into groups based on the type of task dogs must perform. Empirical studies

\section{Journal of}

Veterinary Science \& Medicine

\author{
Kolkmeyer $\mathrm{CA}^{1,2^{*}}$, Schmitz $\mathrm{J}^{3}$ and Gansloßer $\mathrm{U}^{2}$ \\ ${ }^{1}$ Department of Biology, University of Vechta, Germany \\ 2Institut für Zoologie \& Evolutionsforschung mit Phyletischem \\ Museum, Ernst-Haeckel-Haus und Biologiedidaktik, Erbertstr. 1 \\ 07743 Jena, Thuringia, Germany \\ ${ }^{3}$ Department of Biology and Biotechnology, Ruhr-Universität \\ Bochum, Germany \\ *Address for correspondence: \\ Kolkmeyer CA, Fach Biologie, University of Vechta driver- \\ strasee 22, 49377 Vechta, Germany, Tel: 49 -911790 9360; \\ Email: carina.kolkmeyer@uni-vechta.de \\ Submission: 1 April, 2021 \\ Accepted: 5 May, 2021 \\ Published: 10 May, 2021 \\ Copyright: $\odot 2021$ Kolkmeyer CA et al. This is an open access article \\ distributed under the Creative Commons Attribution License, which \\ permits unrestricted use, distribution, and reproduction in any medium, \\ provided the original work is properly cited.
}

examining breed differences in behavior have largely focused on the categorizations established by the American Kennel Club (AKC) and the Fédération Cynologique Internationale (FCI) $(n=365$ breeds, 10 breed groups).

While the FCI classifies the breeds based on their function and phenotype, there is a more modern approach. A study viewed on the geographic origin and molecular relations of dog breeds with the aim to investigate how migration, geographical separation and remixing contributed to the emergence of the dog breeds that exist today [38]. They examined the gene sequences of a total of 1,346 dogs from 161 breeds. The dogs came from all parts of the world, with the exception of Antarctica, and all had very different breeding histories. The resulting breed groups were summarized as clades and the researchers were able to identify 23 clades in total. In this study four breed clades are examined: "shepherds", "retrievers", "terriers" and "hunting Dogs". Within these breed clades, differences in social behavior between neutered and non-neutered males are to be analyzed.

The topic of neutering dogs is always controversial $[39,40,43,21,46]$ and almost all dog owners are confronted with this question at some point. Despite new scientific findings on various health side effects of castration, this surgical procedure is still the method of choice for reproductive control, to remove undesirable behavior and as a preventive measure against some diseases like e.g. testicular cancer in males or pyometra in females [35].

Behavioral reasons relate to problem behavior such as urine marking or, from the point of view of dog owners, inappropriate aggressive behavior. A large-scale Questionnaire study" by Niepel $(2007 ; \mathrm{n}=1010)$ in Germany showed that the reasons vary depending on the dog's gender. According to the study of Niepel male dogs are neutered to $74 \%$ for behavioral and only $21 \%$ for medical reasons. The study by Mertens \& Unshelm (1997) also in Germany revealed similar results [31]. As a reason for castration in males, $69 \%$ stated behavioral problems and only $24 \%$ stated medical causes.

A very important hormone in connection with consequences of castration is cortisol. It is dependent on some neurotransmitters 
(serotonin and oxytocin) and also on the sex hormones. Serotonin, oxytocin and sex hormones (such as testosterone and estrogen) act as important antagonists of cortisol. Accordingly, they have a cortisolsuppressing effect and can reduce anxiety [16].

So neutering a dog because of defensive food aggression, territorial or leash aggression - generally all forms of aggression based on insecurity or self-protection - can even worsen this inappropriate behavior [8].

The main aims of our study are (1) to find out, if neutered and intact dogs of different breeds show differences in the personality traits of extraversion, dog sociability, emotional stability and trainability (based on Turcsán et al. 2011) and (2) to analyse differences in stressindicating behavior or panic and fear between intact and neutered males of the respective breeds.

\section{Materials and Methods}

Dog owners completed the online questionnaires between April and December 2020. Questionnaires were distributed to friends, family, social media, dog schools and breeders. All dogs live with their owners in a family association. For determination of breed we relied on the owners' assignment without checking them e.g. by means of pictures, pedigree excerpts etc. Both dogs kept exclusively as family dogs and also dogs that are led for hunting were included. The dog breeds were categorized according to Parker et al., (2017) into the following breed categories see (Table 1)

\section{Case Studies}

In the first part of the questionnaire, the demographic data of owners (age, gender) and dogs (age, gender, breed and neutering status) were asked. The following questions were about the environment and the daily routine of the dogs. In addition, the problems in living together with the dog and any previous diseases were included. In this work, questions regarding breed, gender and castration status were used for analysis and were evaluated using Microsoft Excel (version 2016). The exact breeds of the participating dogs can be found in the appendix.

\section{BUDAPEST Questionnaire}

The questionnaire from Turcsán et al. (2011) provides information on the four personality traits extraversion, dog sociability, emotional stability and trainability. The questionnaire contains a total of 24 questions that are answered by a 3-point scale. The answers in the four categories were evaluated by forming scores. The results of the questionnaire were analyzed by using Microsoft Excel (version 2016) and SPSS software (by IBM, version 27). The following personality traits (based on Turcsán et al. 2011) were analysed:

\section{Boldness $=$ Extraversion}

(we prefer the last term to avoid confusion with the behavioral supertrait as in the shy-bold-system): Low scores indicate an anxious and insecure character. High scores indicate an open-minded, extrovert character.

\section{Dog Sociability}

Low scores indicate a high tendency for bullying or fighting behavior towards conspecifics. High scores indicate non-suspicious behavior and a more peaceful communication with conspecifics.

\section{Emotional Stability}

Is related to the dog's behavior in stressful situations. Low scores indicate anxious and stressful behaviour (=neuroticism). High scores indicate a calm and emotional stable dog.

\section{Trainability $=$ openness}

Low scores in this trait indicate a less playful and inventive character. Dogs with low scores are considered less open and inquisitive.

\section{Statistical Analyses}

The statistical evaluation and some graphical representation of the results were carried out in SPSS software (by IBM, version 27). The data were tested for normal distribution using the Kolmogorov-Smirnow test [22]. Since all data are not normally distributed, non-parametric tests were used for the analysis. Independent data, e.g. comparisons of intact and castrated males were calculated using the MannWhitney U test [30], comparisons with k-samples, e.g. comparisons of personality traits between breed categories examined by the Kruskal-Wallis $\mathrm{H}$ test ( $\mathrm{H}$ test) [25]. In the second case, if statistical significance was recognized, an adapted post-hoc test was carried out after the Kruskal-Wallis-test. This test includes a comparison of the individual groups including a Bonferroni correction to adjust the level of significance (Dunn-Bonferroni test). In general, the level of significance was set at $\alpha=0.05$. The nominal data of the case studies were statistically analyzed using a multinominal logistic regression to test the differences in dog behavior on a multivariable level.

\section{Results}

\section{BUDAPEST Questionnaires}

Figure 1 shows the differences between the intact and castrated breed clades and between the intact and castrated dogs in the personality traits. Significant differences could be calculated for both

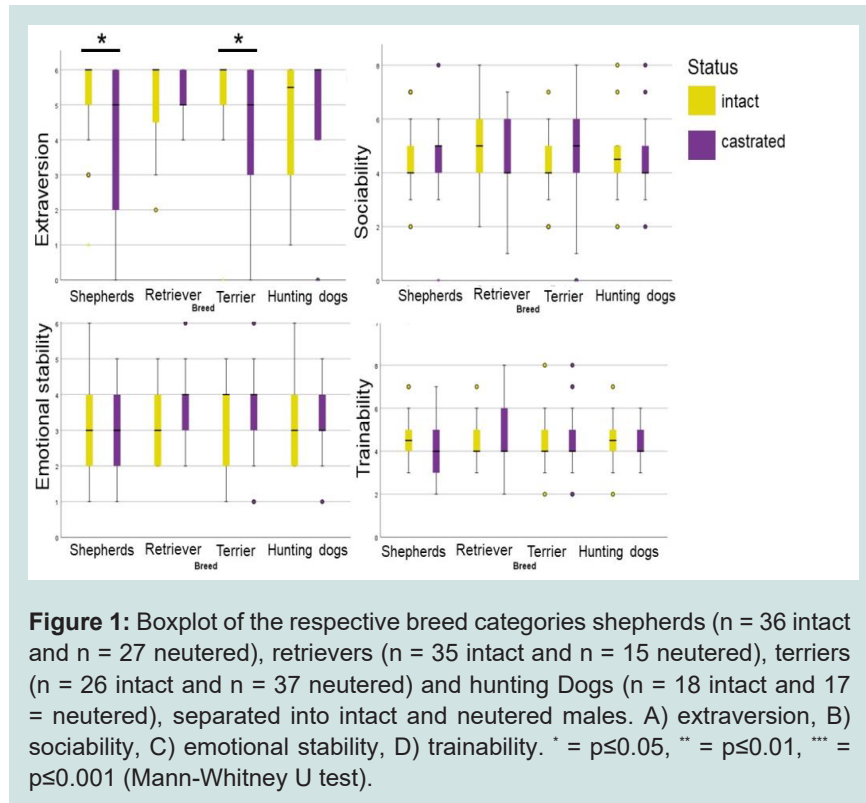


Table 1: The number and categorization of the dog breeds into clades based on the genetic study by Parker et al. 2017.

\begin{tabular}{|c|c|c|c|c|c|}
\hline Hunting Dogs & $\begin{array}{l}\mathrm{n} \text { (case } \\
\text { studies) }\end{array}$ & $\begin{array}{c}\text { n (Budapest } \\
\text { questionnaire) }\end{array}$ & Shepherds & $\begin{array}{l}\mathrm{n} \text { (case } \\
\text { studies) }\end{array}$ & $\begin{array}{c}\text { n (Budapest } \\
\text { questionnaire) }\end{array}$ \\
\hline Dalmatian & 5 & 3 & Australian Shepherd & 42 & 34 \\
\hline German Shorthaired Pointer & 2 & 1 & Bearded Collie & 1 & \\
\hline German Wirehaired Pointer & 2 & 1 & Border collie & 13 & 10 \\
\hline Great Münsterländer & 1 & & Collie & 2 & 1 \\
\hline Irish setter & 7 & 3 & Irish Wolfhound & 1 & 1 \\
\hline Viszla & 0 & 2 & Italian Greyhound & 1 & 1 \\
\hline Weimaraner & 28 & 22 & Shetland Sheepdog (Sheltie) & 2 & \\
\hline Terriers & $\begin{array}{l}\text { n (Case } \\
\text { Studies) }\end{array}$ & $\begin{array}{c}\text { n (Budapest } \\
\text { questionnaire) }\end{array}$ & Retrievers & $\begin{array}{l}\text { n (Case } \\
\text { Studies) }\end{array}$ & $\begin{array}{c}\text { n (Budapest } \\
\text { questionnaire) }\end{array}$ \\
\hline Border Terrier & 2 & 3 & Golden Retriever & 14 & 12 \\
\hline Cairn Terrier & 4 & 4 & Golden x Labrador Retriever & 1 & 1 \\
\hline Irish Terrier & 1 & & Labrador Retriever & 46 & 31 \\
\hline Jack Russell Terrier & 37 & 32 & Noca Sotica Duck Tolling Retriever & & \\
\hline Norfolk Terrier & 2 & 2 & & & \\
\hline Parsons Russell Terrier & 15 & 16 & & & \\
\hline West Highland White Terrier & 3 & 3 & & & \\
\hline Yorkshire Terrier & 2 & 1 & & & \\
\hline
\end{tabular}

the shepherds (U-Test: $\mathrm{p}=0.03)$ and the terriers $(\mathrm{U}=$ Test: $\mathrm{p}=0.04)$. The intact shepherds show higher scores for extraversion ( $\mathrm{Mdn}=6$, $\mathrm{SD}=1.2)$ than the castrated shepherds $(\mathrm{Mdn}=5, \mathrm{SD}=2)$. The data also reveal that the intact terriers have higher extraversion values $(\mathrm{Mdn}=6, \mathrm{SD}=1.3)$ than neutered ones $(\mathrm{Mdn}=5, \mathrm{SD}=1.6)$. No significant differences could be found for the personality traits of sociability (B), emotional stability (C) and trainability (D) (U-test: p> 0.05).

\section{Case Studies}

There are noticeably high scores for stress and insecurity in all four breed categories in comparison to the other behavior problems see (Figure 2).

Aggressive behavior occurred in all breed classes, with the exception of the hunting dogs, more frequently in the castrated than the intact males.

Panic was recorded among shepherds, hunting dogs and retrievers only among neutered dogs. The differences for the castration status are statistically significant for the trait panic (multinomial logistic regression, $\mathrm{p}=0.04$ ). When the effect sizes are considered individually, it is noticeable that the significant value is mainly due to differences in castration status and not due to differences in breed.

No significant differences could be found for the stress/ uncertainty axis, although the shepherds run upwards here and the retrievers comparatively have low values (Figure 2).

\section{Discussion}

Possible explanations for the results can be found in the evaluation of the dog owners as well as in the current research on castration and modern dog breeds.
Using the questionnaire about the dog's personality, differences in extraversion could be determined. Although no major differences between the breed categories of retrievers and hunting dogs could be found, there were significant differences between the shepherds and the terriers. The intact shepherds differ from the neutered shepherds and likewise the intact terriers differ from the neutered terriers. Intact males have higher values in extraversion and are therefore considered to be more open-minded and less fearful than neutered dogs.

This agrees with the results of Hakanen et al. (2020) that intact males are less anxious than neutered males [14]. Kaufmann et al. (2017) also found out on the basis of questionnaire and video analyses that intact males are more likely to perform social behavior than castrated males [21]. The latter often appeared to be more stressed and nervous and consequently stayed more out of the social situation. One explanation for this lies in the abovementioned elimination of the stress-relieving sex hormones and the associated increase of the stress hormone cortisol [16].

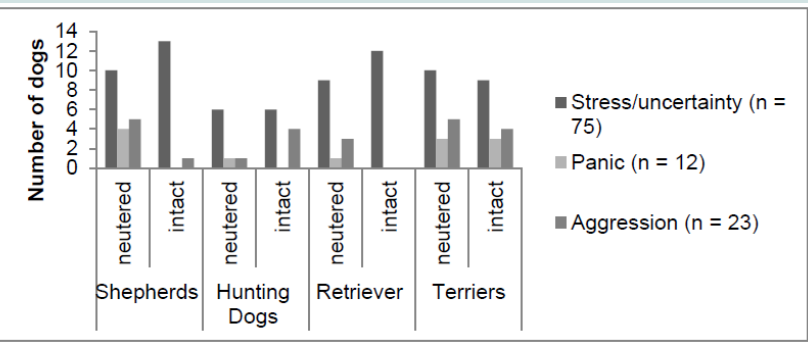

Figure 2: Results of the case studies. Comparison of behavioral problems between neutered $(n=112)$ and Intact $(n=130)$ male dogs $(n=242$ dogs) related to the breeds: shepherds ( $n=36$ intact and 26 neutered), hunting Dogs ( $n=$ 26 intact and 21 neutered), retrievers ( $n=41$ intact and 26 neutered), terriers ( $n=27$ intact, 39 neutered). 
Why the clades of the shepherds and the terriers show significant differences in extraversion can only be speculated at this point. Terriers were bred for independent work such as finding rats and killing prey. They are considered as fearless and impulsive [24]. The higher values of extraversion in non castrated males could therefore be the result of typical breeding effects.

Turcsàn et al. (2011) found that terriers received high scores for extraversion and differ significantly from other breeds [44]. While herding dogs (such as Australian Shepherd or Border Collie) could be classified as low calm, high trainable, low sociable and low bold, (i.e. introverted in the five factor terminology) hunting dog breeds (such as Irish Setters or Pointer) and retrievers (such as Golden or Labrador Retrievers) turned out to be low calm, medium trainable, high sociable and high bold. These data partly coincide with our results. The retrievers had the higher scores for sociability and the hunting dogs were high bold here too. The latter, however, did not turn out to be highly sociable, but achieved lower scores. It must be noted that some representatives of the clade hunting dogs (e.g. German Wirehaired Pointer or Vizsla) can also be found in Turcsán et al (2011) in cluster 2 (low sociable), which in turn corresponds to our results.

The Australian Shepherd was the most frequent breed within this study in the clade of the shepherds. The Australian Shepherd is considered (if kept correctly!) as a balanced, rarely contentious and active herding dog, who is very eager to work [24]. The high extraversion of the Australian Shepherds can also be seen here as the breeding result of a highly motivated working breed [42].

The overall low panic and aggression scores for retrievers and hunting dogs are one of the reasons that both Golden and Labrador Retrievers are among the most popular assistance dog breeds [3]. Hunting dogs are selected to pay more attention to their environment still remaining calm or obedient. In this study, the hunting dogs consisted mainly of Weimaraners, which are considered spirited and sometimes impetuous hunting dogs with a reliable pointing. They are highly vigilant and are therefore not suitable for beginners or people who tend to be a bit casual [24].

The higher values for aggressive behavior in the neutered dogs coincide with the results from Kaufmann et al. (2017). Here the researchers also found by means of questionnaire and video analyses that neutered males are more likely to aggression than intact males, which in turn supports the assumption that aggressive behavior cannot be influenced positively by castration per se (Niepel, 2007) [21,35].

Regarding aggression control, it should also not be disregarded that only types of aggression can be influenced by castration that are dependent on sex hormones.

So from a behavioral point of view, it is controversial to what extent neutering affects social or especially aggressive behavior since dogs may become more aggressive due to the lack of sex hormones [17]. Feddersen-Petersen (2008) writes that aggressive behavior can also indicate a disturbed organism-environment relationship [10]. Nelson et al. 1997, Huntingford \& Turner
Above all, the different types of aggression must be taken into account.

For example, there is also serotonin-dependent aggressive behavior. If the serotonin level is too low, aggressive behavior can be favored. Conversely, however, high serotonin levels can also lead to aggression. The dog breeds Cocker Spaniel and Golden Retriever in particular can have a certain genetic defect, which disrupts the buildup and breakdown of serotonin. As a result, these dogs are prone to aggressive attacks [20].

In partner protection, jealousy behavior and in pair bonding, it is also not the sex hormones that play a role, but two other hormones: oxytocin and vasopressin [29,2]. The latter evokes the aggressive behaviors occurring in partner protection and in jealousness. Oxytocin is important above all for a positive, social bonding with a conspecific. In order for developing a bond, however, vasopressin must be produced as a preliminary stage before oxytocin production. Accordingly, in general terms, every bond also includes a certain degree of jealousy. Consequently, partner protection and jealous behavior cannot be eliminated by castration, as Bielsky \& Young (2004) were able to show in mice and rats.

In addition to the hormone-related behaviors, there are also some that are influenced by transmitters. Aggressive behavior that occurs in the course of self-defense is controlled, for example, by norepinephrine. This catecholamine, also known as the fighting hormone, is preferred in a stressful situation when it comes to protecting or defending yourself. The norepinephrine acts primarily in a self-rewarding learning effect, which means that successful courses of action are learned and saved (an example would be the learned leash aggression). Again, even with this type of aggressive behavior, castration is not very promising, as there is no connection between the sex hormones and self-defense $[1,34]$. In our study, aggressive behavior also occurs among neuters and there were no significant differences, i.e. neutering does not seem to have a positive effect on aggressive behavior. This is an important aspect considering aggression as a common reason for castration.

The increased panic with more neutered animals again provides an indication of the behavioral consequences of neutering, which was also found by Zink et al. (2014) in castrated Vizslas [45]. Our results show only significance for the castration status, not for the breeds, which could be an indication that panic behavior occurs more frequently in neutered males regardless of the breed. If the stress hormone cortisol is included again, as already described in the introduction, it becomes clear that anxiety-related aggressions are controlled by cortisol and that testosterone as an inhibitor is no longer present as a result of castration [16].

Serpell \& Hsu (2005) and also Kubinyi et al. (2009) as well as Starling et al. (2013) showed that the neutered males and females were the most insecure dogs in comparison to the intact ones. In addition, the neutered dogs of both sexes were also the less sociable dogs $[41,26,42]$.

In Müllers study (2017), the representatives of the shepherds clade showed fewer distance-keeping signals than the retriever clade. The herding dogs seem to be generally more open-minded and open towards conspecifics, so that they are often assessed by their dog 
owners as more excitable. This less developed distancing tendency can possibly due to the breeding effects of shepherds for herding work [33].

However, the results regarding the terriers were surprising. These are considered fearless energetic and proactive dogs with low selfprotective behavior and a high tendency to react with aggression when threatened [24]. The fact that the terriers do not distinguish themselves significantly from the other breed categories in any emotional characteristic was therefore an unexpected result.

Beside the genetic and morphological aspects, the experiences and handling of the dog certainly play a major role in how castration affects a dog, because each animal tends to coping strategies $[9,10]$. Likewise, when it comes to castration, placebo effect should always be taken into account [47], which is based on a certain expectation of dog owners to improve or remove specific behaviors through castration

Our results once again show the importance of individual-based informed decision-making processes regarding this ever-present topic.

\section{References}

1. Archer J (1997). Why do people love their pets? Evolution and Human behavior 18: 237-259.

2. Bielsky IF, Young LJ (2004) Oxytocin, vasopressin and social recognition in mammals. Peptides 25: 1565-1574.

3. Bogaerts E, Moons CP, Van Nieuwerburgh F, Peelman L, Saunders JH (2019). Rejections in an non-purpose bred assistance dog population: Reasons, consequences and methods for screening. PloS one 14: e0218339.

4. Botigué LR., Song S, Scheu A, Gopalan S, Pendleton AL, et al. (2017) Ancient European dog genomes reveal continuity since the Early Neolithic. Nature communications 8: 1-11.

5. Bradley J (2011) The relevance of breed in selecting a companion dog. The relevance of breed in selecting a companion dog.

6. Brewer DJ, Terence CS, Phillips A (2002) Dogs in antiquity: Anubis to Cerberus the origins of the domestic dog (egyptology). Warminster: Aris \& Phillips.

7. Crockford SJ, Kuzmin YV (2012). Comments on Germonpré et al., Journal of Archaeological Science 36, 2009 "Fossil dogs and wolves from Palaeolithic sites in Belgium, the Ukraine and Russia: osteometry, ancient DNA and stable isotopes”, and Germonpré, Lázkičková- Galetová, and Sablin, Journal of Archaeological Science 39, 2012 "Palaeolithic dog skulls at the Gravettian Předmostí site, the Czech Republic". Journal of Archaeological Science 39: 2797-2801.

8. Farhoody P, Zink MC (2010). Behavioral and physical effects of spaying and neutering domestic dogs (Canis familiaris). Unpublished summary of a Masters thesis, Hunter College, New York, NY.

9. Feddersen-Petersen, DU (2004). Hundepsychologie: Sozialverhalten und Wesen, Emotionen und Individualität. (4edn), Kosmos, Stuttgart.

10. Feddersen-Petersen DU (2008) Ausdrucksverhalten beim Hund: Mimik und Körpersprache; Kommunikation und Verständigung. Kosmos.

11. Freedman AH., Wayne RK (2017) Deciphering the origin of dogs: From fossils to genomes. Annual review of animal biosciences 5: 281-307.

12. Gansloßer U, Kitchenham K(2019) Forschung trifft Hund: Neue Erkenntnisse zu Sozialverhalten, geistigen Leistungen und Ökologie. Kosmos.

13. Germonpré M, Sablin MV, Stevens RE, Hedges RE, Hofreiter M (2009) Fossil dogs and wolves from Palaeolithic sites in Belgium, the Ukraine and Russia: osteometry, ancient DNA and stable isotopes. Journal of

\section{Archaeological Science 36: 473-490}

14. Hakanen E, Mikkola S, Salonen M, Puurunen J, Sulkama S, et al. (2020) Active and social life is associated with lower non-social fearfulness in pet dogs. Scientific reports 10: 1-13.

15. Heberer U, Brede N, Mrozinski N (2017) Aggressionsverhalten beim Hund. Franckk-Kosmos Verlags-GmbH \& Co.KG, Stuttgart.

16. Henry JP, Stephens PM (1977) Stress, Health, and the Social Environment A Sociobiologic Approach to Medicine. (1stedn) Springer-Verlag New York Inc.

17. Hoferichter A (2015) Kastration von Hündinnen - mit falschen Zahlen operiert. Süddeutsche Zeitung.

18. Howell TJ, Bennett PC (2011) Puppy power! Using social cognition research tasks to improve socialization practices for domestic dogs (Canis familiaris). Journal of Veterinary Behavior 6: 195-204.

19. Immelmann K(1982). Wörterbuch der Verhaltensforschung Paul Parey Verlag.

20. Jacobs C, Van der Broec W, Simoens P (2007) Neurons expressing serotonin1B receptor in the basolateral nuclear group of the amygdale in normally behaving and aggressive dogs. Brain Research 1136: 102-109.

21. Kaufmann CA, Forndran S, Stauber C, Woerner K, et al. (2017) The social behaviour of neutered male dogs compared to intact dogs (Ca-nis lupus familiaris): Video analyses, questionnaires and case studies. Vet Med Open J 2: 22-37

22. Kolmogorov A (1933). Sulla determinazione empirica di una lgge di distribuzione. Inst. Ital. Attuari, Giorn. 4: 83-91.

23. Koyasu H, Kikusui T, Takagi S, Nagasawa $M(2020)$ The Gaze Communications Between Dogs/Cats and Humans: Recent Research Review and Future Directions. Front in Psychol 11: 3687.

24. Krämer EM (2019): 250 Hunderassen. Ursprung, Wesen, Haltung (3rdedn). Stuttgart: Kosmos.

25. Kruskal WH, Wallis WA (1952) Use of ranks in one-criterion variance analysis. Journal of the American statistical Association 47: 583- 621.

26. Kubinyi E, Turcsán B, Miklósi A (2009) Dog and owner demographic characteristics and dog personality trait associations. Behavioural Processes 81: 392-401.

27. Lorenz KP, Kolkmeyer CA, Gansloßer U (2018) Comparison of the Socia Behaviour of Intact and Neutered Female Domestic Dogs (Canis lupus familiaris): Video Analyses. Journal of Dairy \& Veterinary Sciences 8.

28. Lorenz KP, Kolkmeyer CA \& Gansloßer U (2019) Comparison of the Social Behaviour of Intact and Neutered Female Domestic Dogs (Canis Lupus Familiaris): Questionnaires and Case Studies. Journal of Dairy and Veterinary Sciences 12: 1-8.

29. MacLean EL, Gesquiere LR, Gruen ME, Sherman BL, Martin WL, et al (2017) Endogenous Oxytocin, Vasopressin, and Aggression in Domestic Dogs. Front. Psychol 8: 1613.

30. Mann HB, Whitney DR (1947). On a test of whether one of two random variables is stochastically larger than the other. The annals of mathematical statistics 50-60.

31. Mertens PA, Unshelm J (1997) Castrating canines-legal situation, potential problems, and current practice. Kleintierpraxis 42: 631.

32. Miklósi Á (2011). Hunde: Evolution, Kognition und Verhalten. FranckhKosmos.

33. Müller B(2017) Elemente des Konfliktmanagements unter Berücksichtigung phylogenetischer und morphologischer Einflüsse bei Canis lupus f. Familiaris. Masterthesis, Universität Giessen.

34. Nelson, RandyJ (1997) The use of genetic "knockout" mice in behavioral endocrinology research." Hormones and Behavior 31: 188-196.

35. Niepel G (2007). Kastration beim Hund: Chancen und Risiken-eine Entscheidungshilfe. Kosmos. 
36. O'Heare J(2009). Die Neuropsychologie des Hundes. Animal-LearnVerlag.

37. Ovodov ND, Crockford SJ, Kuzmin YV, Higham TF, Hodgins GW, (2011) A 33,000-year-old incipient dog from the Altai Mountains of Siberia: evidence of the earliest domestication disrupted by the Last Glacial Maximum. PloS one 6: e22821.

38. Parker HG, Dreger DL, Rimbault M, Davis BW, Mullen AB, et al. (2017) Genomic analyses reveal the influence of geographic origin, migration, and hybridization on modern dog breed development. Cell reports. 19: 697-708.

39. Reichler IM (2009) Auswirkungen der Kastration auf den Stoffwechsel, den Bewegungsapparat und die Tumorgenese. 55. Jahrestagung der DGKDVG in Berlin.

40. Reichler IM (2010) Gesundheitliche Vor-und Nachteile der Kastration von Hündinnen und Rüden. Schweizer Archiv für Tierheilkunde 152: 267- 272.

41. Reichler IM (2010b) Kastrationsnebenwirkungen Harninkontinenz und Welpenfell bei der Hündin. Tierärztliche Praxis. Ausgabe K, Kleintiere 38 : 157-162.
42. Serpell JA, Hsu YA (2005) Effects of breed, sex, and neuter status on trainability in dogs. Anthrozoös, 18: 196-207.

43. Starling MJ, Branson N, Thomson PC, McGreevy PD (2013) Age, sex and reproductive status affect boldness in dogs. The Veterinary Journal, 197: 868-872.

44. Sundburg CR, Belanger JM, Bannasch DL, Famula TR, Oberbauer AM (2016). Gonadectomy effects on the risk of immune disorders in the dog: a retrospective study. BMC veterinary research 12: 1-10.

45. Turcsán B, Kubinyi E, Miklósi Á (2011). Trainability and boldness traits differ between dog breed clusters based on conventional breed categories and genetic relatedness. Applied Animal Behaviour Science 132: 61-70.

46. Zink MC, Farhoody P, Elser SE, Ruffini LD, Gibbons TA (2014) Evaluation of the risk and age of onset of cancer and behavioral disorders in gonadectomized Vizslas. Journal of the American Veterinary Medical Association, 244: 309-319.

47. Zlotnick M, Corrigan VK, Griffin E, Alayon M, Hungerford L (2019) Incidence of Health and Behavior Problems in Service Dog Candidates Neutered at Various Ages. Front Vet Sci 6: 334.

\section{Acknowledgement}

We thank all people who helped us to distribute the online questionnaires via social media and all dog owners who participated in our questionnaire study. We are also grateful for the support of all members of our mammalian behaviour study group for helpful discussions. 